\title{
> O entre-lugar de Ponciá Vicêncio: $O$ vazio como resistência
}

> The space in-between of Ponciá Vicêncio: Emptiness as resistance

\section{por Roberta de Araújo Lantyer Duarte}

Mestranda em Literatura e Cultura na linha de pesquisa Estudos de Teorias e Representações Literárias e Culturais do Programa de Pós-Graduação em Literatura e Cultura da Universidade Federal da Bahia (UFBA). E-mail beta_lantyer@hotmail.com. ORCID: 0000-0001-5894-0327.

\section{Resumo}

Este artigo discute a imagem do vazio da personagem Ponciá Vicêncio no romance de mesmo nome, escrito por Conceição Evaristo. A sensação de vazio da personagem será pensada como resistência a partir da ideia de banzo, um estado em que o tempo do sujeito não é o tempo opressor da sociedade capitalista. Além disso, na narrativa, esse estado de alma permite a rememoração das dores e lutas dos antepassados de Ponciá - pensados a partir do personagem Vô Vicêncio. Por fim, esse banzo levará à herança que Vô Vicêncio deixou para Ponciá - a loucura. O conceito de entre-lugar, de Silviano Santiago, será acionado a fim de pensar o devir-revolucionário da Literatura Negra.

Palavras-chave: Conceição Evaristo. Ponciá Vicêncio. Vazio. Banzo. Resistência.

\begin{abstract}
This article discusses the image of the emptiness of the character Ponciá Vicêncio in the novel of the same name, written by Conceição Evaristo. The character's "empty" feeling will be thought of as resistance from the idea of banzo, a state in which the subject's time is not the oppressive time of capitalist society. In addition, in the narrative, this state of soul allows for the remembrance of the pains and struggles of Ponciá's ancestors thought through the character Vô Vicêncio. Finally, this banzo will lead to the inheritance that Vô Vicêncio left for Ponciá - madness. Silviano Santiago's concept of space in-between will be activated in order to think about the becoming-revolutionary of Black Literature.
\end{abstract}

Keywords: Conceição Evaristo. Ponciá Vicêncio. Empty. Banzo. Resistance. 


\section{Introdução}

"Falar, escrever, significa: falar contra, escrever contra"1

Inicialmente, acho importante deixar claro que parto da convicção de que nenhum texto está desprovido de posicionamento. Qualquer discurso demonstra relações de poder intimamente ligadas com o sujeito que escreve/fala. Afinal, o sujeito, também ele, não é um ser flutuante, isento, sozinho; todo sujeito e, consequentemente, o discurso que ele emite, está inserido em uma cultura, uma história. Sendo assim, ao se analisar qualquer texto (seja ele literário ou não) devemos perceber de onde ele está sendo emitido, as posições de enunciação, como afirma Stuart Hall:

As práticas de representação implicam sempre em posições de onde se fala ou se escreve - as posições de enunciação. As teorias sobre enunciação mais recentes sugerem que, não obstante falarmos, por assim dizer, "em nosso nome", de nós mesmos e com base em nossa própria experiência, quem fala e a pessoa de quem se fala nunca são idênticos, nunca estão exatamente no mesmo lugar. [...] O "eu" que aqui escreve, por certo, tem também de ser pensado, ele mesmo com o "enunciado". Todos nós escrevemos e falamos desde um lugar e um tempo particulares, desde uma história e uma cultura específicas. O que dizemos está sempre "em contexto", posicionado. ${ }^{2}$

Entendendo a importância de posicionar a enunciação, deixo claro que escrevo este artigo do meu lugar de mulher branca; subalternizada por ser mulher, mas cujo corpo não está marcado pelo racismo sofrido pelos corpos negros. Contudo, este meu corpo, afetado pela literatura afro-brasileira de Conceição Evaristo, assume a importância de se falar dessa história que não ninam, mas incomodam; dessas histórias que questionam as molduras, que propõem uma mudança das representações do corpo negro e do corpo feminino. A literatura afro-brasileira de Conceição Evaristo vai falar/escrever contra as representações comuns aos negros na literatura canônica brasileira, contra os

\footnotetext{
${ }^{1}$ Silviano Santiago, "O entre-lugar do discurso latino-americano", 2000, p. 17.

${ }^{2}$ Stuart Hall, "Identidade Cultural e Diáspora", 1998, p. 68.
} 
silenciamentos, contra a ocultação das violências sofridas pelos povos negros desde a escravidão.

A partir disto, é preciso chamar atenção para o lugar da escrita negra de Conceição Evaristo. A voz de Evaristo é voz da escrevivência - essa escrita que parte dos "chamados das vizinhas debruçadas sobre as janelas, ou nos vãos das portas contando em voz alta uma para outras as suas mazelas, assim como as suas alegrias"3 e que não serve para "ninar os da casa grande' e sim para incomodá-los em seus sonos injustos"4. Segundo Lívia Natália de Souza5 ${ }^{5}$ a Literatura Negra, feita por Conceição Evaristo e pensada por ela a partir do conceito teórico de escrevivência, pode ser lida como Literatura Menor, no sentido dado por Deleuze e Guatarri'. Nas palavras da autora, essa escrita compromete-se a "[...] abrir mão do espaço narcísico da literatura para dar corpo amplo, coletivo à sua fala, eis o gesto destes textos"7. Ou seja, entre muitas de suas características que fazem que com que possamos entender essa escrita a partir do conceito de Literatura Menor, está o agenciamento coletivo de enunciação 8 ou a escrevivência. A partir da escrevivência, Conceição Evaristo, mulher e negra, expressa outras possibilidades para os corpos das mulheres negras há muito representadas na literatura brasileira. A Literatura Negra de Conceição Evaristo e de muitas(os) outras e outros, sujeitos/escritores subalternizados assume esse papel de insubordinação:

Insubordinação de poder se evidenciar, muitas vezes, desde uma escrita que fere "as normas cultas" da língua, caso exemplar de Carolina Maria de Jesus, como também pela escolha da matéria narrada. [...] A

\footnotetext{
${ }^{3}$ Conceição Evaristo, Da grafia-desenho de minha mãe um dos lugares de nascimento de minha escrita, 2005, n.p.

${ }^{4}$ Ibidem, n.p.

${ }^{5}$ Lívia Maria Natália de Souza, "Uma reflexão sobre os discursos menores ou a escrevivência como narrativa subalterna", 2018, p. 25-43.

${ }^{6}$ Gilles Deleuze e Félix Guatarri, "O que é uma Literatura menor", 2014.

${ }^{7}$ Lívia Maria Natália de Souza, "Uma reflexão sobre os discursos menores ou a escrevivência como narrativa subalterna", 2018, p. 41.

${ }^{8}$ Gilles Deleuze e Félix Guatarri, “O que é uma Literatura menor”, 2014, p. 11.
} 
nossa escrevivência não pode ser lida como histórias para "ninar os da casa grande" e sim para incomodá-los em seus sonos injustos.?

É nesse sentido de insubordinação que podemos entender a forma de expressão - e não de representação - feita por essa literatura. Aqui, sugiro a expressão em contraposição à representação, conforme pensado por Souza. A autora afirma que, ao contrário da representação feita pela literatura hegemônica, a Literatura Negra não se subordina à lógica eurocêntrica da mímesis: "Operando para além da relação entre vida e ficção, a expressão alcança elementos, cenas e formas de fazer que a representação guarda no limiar ficção/realidade"10. A expressão está no âmbito do devir; não busca atingir uma forma mimética, "mas encontrar a zona de vizinhança"11. É disso que trata "os chamados das vizinhas na janela" da escrevivência de Conceição Evaristo. Essa literatura não conta as próprias lembranças - individuadas; não peca pelo excesso, nem pela falta de imaginação; ao contrário, descobre a "potência de um impessoal" ${ }^{12}$ Assim, Ponciá Vicêncio é uma mulher negra, e como "elo e herança de uma memória reencontrada pelos seus" ${ }^{\prime 13}$, agencia memórias coletivas e agitase num rio de resistências.

Falemos um pouco sobre as representações para, posteriormente, localizarmos as expressões e devires da literatura feita por Conceição Evaristo, especificamente na obra Ponciá Vicêncio, romance de 2003.

\section{Algumas palavras sobre o cânone literário}

A literatura canônica brasileira é marcada por ausências de representações ou por representação estereotipada dos negros e, mais

\footnotetext{
${ }^{9}$ Conceição Evaristo, Da grafia-desenho de minha mãe um dos lugares de nascimento de minha escrita, 2005, n.p.

${ }^{10}$ Lívia Maria Natália de Souza, "Uma reflexão sobre os discursos menores ou a escrevivência como narrativa subalterna", 2018, p. 29.

${ }^{11}$ Gilles Deleuze, "A literatura e a vida", 1997, p. 11.

12 Ibidem, p. 13.

${ }^{13}$ Conceição Evaristo, Ponciá Vicêncio, 2003, p. 128.
} 
especificamente, das mulheres negras. O cânone literário é uma seleção reduzida de textos ditos clássicos, os quais, segundo Italo Calvino, "são livros que exercem uma influência particular quando se impõem como inesquecíveis e também se ocultam nas dobras da memória, mimetizando-se como inconsciente coletivo ou individual"14. Mas quais os critérios dessa seleção?

Não acho interessante nem viável pensar de forma objetiva e sistemática numa resposta a essa pergunta, de forma a criar uma lista de suposições. O que pretendo aqui é, antes, pensar qual sociedade selecionou as obras as que chamamos hoje de cânone literário brasileiro, as tais obras primas? Em que moldes de pensamento? Baseado em que saber-poder?

Nesse sentido, cito aqui o primeiro volume do livro História da Literatura Brasileira, de Silvio Romero, publicado em 1888:

\begin{abstract}
A literatura no Brasil, a literatura em toda a América, tem sido um processo de adaptação de ideias europeias às sociedades do continente. Esta adaptação nos tempos coloniais foi mais ou menos inconsciente; hoje tende a tornar-se compreensiva e deliberadamente feita. Da imitação tumultuária, do antigo servilismo mental, queremos passar à escolha, à seleção literária e científica. A darwinização da crítica é uma realidade tão grande quanto é a da biologia. ${ }^{15}$
\end{abstract}

Partindo do darwinismo social, Silvio Romero, no mesmo livro, caracteriza a nação brasileira: "A raça ariana, reunindo-se aqui a duas outras totalmente diversas, contribuiu para a formação de uma sub-raça mestiça e crioula, distinta da europeia"16. Anos mais tarde, ainda sobre a literatura brasileira, Antônio Cândido dirá: "Comparada às grandes literaturas, a nossa literatura é pobre e fraca. Mas é ela, e não a outra, que nos exprime. Se não for amada, não revelará a sua mensagem; e se não a amarmos, ninguém o fará por nós"17.

A partir dessas citações de textos importantes para pensarmos o cânone literário, arrisco dizer que a formação do cânone está ligada a ideias de

\footnotetext{
${ }^{14}$ Italo Calvino, Por que ler os clássicos, 1993, p. 10-11.

${ }^{15}$ Silvio Romero, História da literatura brasileira, 1888, p. 4.

${ }^{16}$ Ibidem, p. 20.

${ }^{17}$ Antônio Cândido, Formação da literatura brasileira - vol. 1, (1959) 2000, p. 10.
} 
orientalismo, pensamento que não só nomeia o oriental como oriental, mas que constrói esse Outro oriental e produz efeito sobre ele, influenciando até mesmo os chamados orientais. Sobre o orientalismo, Said afirma que sua essência é a "distinção inextirpável entre a superioridade ocidental e a inferioridade oriental"18. Said dirá que o orientalismo, teoria que pode ser verificada desde os escritos do século XIX, se baseia em argumentos simples e fáceis de apreender e que, apesar de se utilizar de generalidades e ter "como certa a sua condição de verdade científica"19, é uma teoria que funciona de forma persistente, até os dias de hoje, justificando a dominação Ocidental e sendo reforçada por ela. Ora, podemos pensar o orientalismo como chave para o colonial, nações subjugadas a outras. A mesma lógica se aplicou no Brasil e faz perdurar a ideia de que o que é europeu/ocidental é superior ao que surge de terras colonizadas. Essa persistência da teoria orientalista pode ser percebida na citação feita acima, referente às primeiras páginas escritas por Antônio Cândido no livro Formação da Literatura Brasileira.

Edward Said afirma ainda que o orientalismo foi submetido ao darwinismo e ao racismo, por exemplo. O darwinismo, citado por Sílvio Romero em 1888, ligado ao orientalismo, me faz inferir que o cânone literário brasileiro foi formado a partir do eurocentrismo e da ideia de uma superioridade ariana. Talvez seja esse o motivo de um cânone literário em sua imensa maioria branco e masculino. Mas não está apenas na autoria a problemática das grandes obras brasileiras, mas em toda uma representação de sujeito, também baseada nesses saberes.

Regina Dalcastagnè, no livro Literatura brasileira contemporânea: um território contestado, reserva o último capítulo para falar acerca de uma pesquisa feita com 258 romances de autores brasileiros com publicação entre 1990 e 2004.

\footnotetext{
${ }^{18}$ Edward Said, “O âmbito do orientalismo", 1990, p. 52.

${ }^{19}$ Ibidem, p. 56.
} 
A intenção da pesquisa seria verificar quais as representações são privilegiadas nas obras literárias brasileiras:

\begin{abstract}
Os dados mostram que o romance contemporâneo privilegia a representação de um espaço social restrito. Suas personagens são, em sua maioria, do sexo masculino das classes médias. Sobre outros grupos, imperam os estereótipos. As mulheres brancas aparecem como donas de casa; as negras como empregadas domésticas ou prostitutas; os homens negros, como bandidos. Assim, o campo literário, embora permaneça imune às críticas que outros meios de expressão simbólica costumam receber, reproduz os padrões de exclusão da sociedade brasileira ${ }^{20}$.
\end{abstract}

No decorrer do capítulo citado, intitulado "Um mapa de ausências", Dalcastagnè explica como se deu a pesquisa e ressalta que se trata de pesquisa predominantemente quantitativa, sem se dedicar à análise de ironias nem sarcasmos, sem a leitura das entrelinhas, "não observa as sutis trocas de olhares dos personagens. Porém, se o foco da representação literária está em determinados grupos sociais, fazendo com que outros desapareçam (ou quase), então, quem está trocando os olhares?"21. Apesar de não se tratar de pesquisa que chegue a uma conclusão sobre o que está sendo dito/defendido nas representações de determinados sujeitos na literatura contemporânea brasileira, os seus resultados são sintomáticos para se pensar a continuidade do pensamento orientalista, perpassada pelo racismo e misoginia (para citar apenas alguns), que juntos irão decidir quem pode falar/escrever e quem não pode, quem pode ser representado e quem não pode, e de que forma determinados grupos sociais serão representados. Mas nem só disso vive a literatura brasileira. Falemos então de quem impõe uma brecha, uma rachadura, em meio a todos esses saberes-poderes já estruturados na sociedade brasileira, de quem se esforça para subverter o cânone caracterizado anteriormente.

\footnotetext{
${ }^{20}$ Regina Dalcastagnè, Literatura brasileira contemporânea: um território contestado, 2016, n.p.

${ }^{21}$ Ibidem, n.p.
} 


\section{Ponciá Vicêncio e seu vazio}

O romance Ponciá Vicêncio, publicado em 2003, conta a história de uma personagem subalternizada - ou subalterna; esse Outro que é, insistentemente, pensado a partir da sombra do $\mathrm{Eu}^{22}$ - conta os caminhos, traumas, sonhos e afetos da personagem de mesmo nome. O livro é separado por capítulos, sem a indicação de nomes. A história não é contada de forma linear, mas o leitor vai tecendo a história de Ponciá a partir da leitura seguida dos capítulos, que contam a história da personagem desde muito nova, criança de colo ainda, até a idade adulta, passando pela apresentação de seus familiares e pelos acontecimentos traumáticos da protagonista. O narrador conhece Ponciá em toda sua complexa intimidade e nos conta seus sonhos, desencantos, traumas e vazios; sem exagerar nos adjetivos, já que a história de sofrimento de Ponciá é seca e dolorida e seus caminhos dispensam firulas e rodeios.

Ponciá Vicêncio - mulher, negra, pobre, vinda do interior para a capital, doméstica - partilha com seus antepassados as memórias coletivas de sofrimento desde a escravidão. Esses sofrimentos estão estampados em seu próprio nome, que leva, no Vicêncio, o sobrenome da família dos brancos donos dos seus antepassados escravizados. "O tempo passou deixando a marca daqueles que se fizeram donos das terras e dos homens"23. O seu nome só traz ainda mais para seu corpo, o sofrimento dos seus:

Quando mais nova, sonhara até um outro nome para si. Não gostava daquele que lhe deram. Menina, tinha o hábito de ir à beira do rio e lá, se mirando nas águas, gritava o próprio nome: Ponciá Vicêncio! Ponciá Vicêncio! Sentia-se como se estivesse chamando outra pessoa. Não ouvia o seu nome responder dentro de si. Inventava outros. Pandá, Malenga, Quiete, nenhum lhe pertencia também. Ela, inominada, tremendo de medo, temia a brincadeira, mas insistia. A cabeça rodava no vazio, ela vazia se sentia sem nome. Sentia-se ninguém. Tinha, então, vontade de choros e risos. $^{24}$

${ }^{22}$ Gayatri Chakravorty Spivak, Pode o subalterno falar?, 2010, p. 46.

${ }^{23}$ Conceição Evaristo, Ponciá Vicêncio, 2003, p. 29

${ }^{24}$ Ibidem, p. 19. 
Ponciá não se identificava com o nome. Os antepassados dela receberam o mesmo sobrenome dos seus donos - a família Vicêncio - e, como uma marca, esse sobrenome a fazia lembrar de todos os sofrimentos dos seus antepassados. $\mathrm{O}$ seu nome não a representava, não fazia nenhum sentido para ela. Na época da escravidão, era comum os escravizados receberem o mesmo sobrenome dos seus senhores:

\begin{abstract}
Ponciá Vicêncio sabia que o sobrenome dela tinha vindo desde antes do avô de seu avô, o homem que ela havia copiado de sua memória para o barro e que a mãe não gostava de encarar. O pai, a mãe, todos continuavam Vicêncio. Na assinatura dela, a reminiscência do poderio do senhor, de um tal coronel Vicêncio. $O$ tempo passou deixando a marca daquele que se fizeram donos das terras e dos homens. E Ponciá? De onde teria surgido Ponciá? Por quê? Em que memória do tempo estaria escrito o significado do nome dela? Ponciá Vicêncio era para ela um nome que não tinha dono. ${ }^{25}$
\end{abstract}

O rio, que a menina faz de espelho e tentativa de autoreconhecimento, flui à medida que a menina Ponciá cresce, mas suas águas estão em movimento desde antes do seu nascimento. $O$ que quero dizer é que os antepassados têm papel fundamental no vir a ser de Ponciá. Na relação de Ponciá com Vô Vicêncio, podemos perceber isso com maior intensidade. Ele foi o primeiro homem que Ponciá conheceu e tem grande importância na história de Ponciá. Vô Vicêncio morreu quando Ponciá ainda era criança de colo. Ponciá se apropria dos gestos de Vô Vicêncio. Ela se identifica com ele, mas essa identificação não é baseada simplesmente numa ligação afetiva entre os dois indivíduos - Ponciá e Vô Vicêncio; afinal, Ponciá era ainda criança de colo. Trata-se aqui de uma identificação ancestral, decorrente de um passado coletivo em comum. São as marcas da diáspora negra. Trata-se da identidade cultural conceituada por Stuart Hall e que, na literatura, se materializa no corpo de Ponciá Vicêncio:

Sob esse aspecto, a identidade cultural não é jamais uma essência fixa que se mantenha, imutável, fora da história e da cultura. Nem é, dentro de nós, algum espírito transcendental e universal no qual a história não fez marcas fundamentais. Também não é 'de uma vez para sempre'. Não é uma origem fixa à qual possamos fazer um retorno final e absoluto. E, é claro, não é um simples fantasma. Mas é alguma coisa - não um mero artifício da imaginação. Tem suas histórias - e as histórias, por sua vez, têm seus efeitos reais, materiais e simbólicos. O passado continua a nos falar. Mas já

${ }^{25}$ Ibidem, p. 29. 
não é como um simples passado factual que se dirige a nós, pois nossa relação com ele, como a relação de uma criança com a mãe, é sempre intermédio de memória, fantasia, narrativa e mito. As identidades culturais são os pontos de identificação, os pontos instáveis de identificação ou sutura, feitos no interior dos discursos da cultura e da história. Não uma essência, mas um posicionamento. Donde haver sempre uma política da identidade, uma política de posição, que não conta com nenhuma garantia absoluta numa "lei de origem" sem problemas, transcendental. ${ }^{26}$

Nesse sentido, Vô Vicêncio e o que o personagem traz como história na narrativa é um ponto de identificação importante para Ponciá, a ponto da menina lhe imitar os gestos inconscientemente - já que isso se dá assim que ela começa a andar:

Andava com um dos braços escondido às costas e tinha a mãozinha fechada com se fosse cotó. Fazia quase um ano que Vô Vicêncio tinha morrido. Todos deram de perguntar por que ela andava assim. Quando o avô morreu, a menina era tão pequena! Como agora imitava o avô? Todos se assustavam. A mãe e a madrinha benziam-se quando olhavam para Ponciá Vicêncio. ${ }^{27}$

Ponciá não se torna Vô Vicêncio, não retorna a um passado absoluto, mas a importância daquilo que a precedeu, da história de sofrimento e luta dos seus antepassados, é corporificada pela imitação dos gestos do avô. Vô Vicêncio fora escravizado. Durante anos, viveu com mulher e filhos na lida do canavial. O seu sangue e o dos seus familiares fora derramado para enriquecer o senhor. Quatro dos seus filhos, nascidos já no período da Lei do Ventre Livre, foram vendidos. Em momento de desespero, Vô Vicêncio matou a esposa e, na tentativa de se matar, com a mesma foice, se autoflagelou e perdeu a mão. Não conseguiu se matar, pois foi impedido; mas ficou com o "braço cotó" e "louco, chorando e rindo"28. Essa seria a herança de Vô Vicêncio, destinada a Ponciá - essa loucura, os choros e risos. Essa herança começará a se manifestar em Ponciá através dos vazios, do apartar-se de si mesma:

Nas primeiras vezes que Ponciá Vicêncio sentiu o vazio na cabeça, quando voltou a si, ficou atordoada. O que havia acontecido? Quanto tempo tinha ficado naquele estado? Tentou relembrar os fatos e não sabia como tudo se dera. Sabia apenas que, de uma hora para outra era como se um buraco

\footnotetext{
${ }^{26}$ Stuart Hall, "Identidade Cultural e Diáspora”, 1988, p. 70.

${ }^{27}$ Conceição Evaristo, Ponciá Vicêncio, 2003, p. 16.

${ }^{28}$ Ibidem, p. 51.
} 
abrisse em si própria, formando uma grande fenda, dentro e fora dela, um vácuo com o qual ela se confundia. Mas continuava, entretanto, consciente de tudo ao redor. Via a vida e os outros se fazendo, assistia aos movimentos alheios se dando, mas se perdia, não conseguia saber de si. No princípio, quando o vazio ameaçava a encher a sua pessoa, ela ficava possuída de medo. Agora gostava da ausência, na qual ela se abrigava, desconhecendose, tronando-se alheia de seu próprio eu. ${ }^{29}$

O vazio de Ponciá é fruto do peso das suas perdas, da vida escrava que ainda insistia em permanecer, da saudade dos seus familiares e do barro, fruto das memórias de sofrimento de seus antepassados e, por que não dizer, da saudade de uma África nunca conhecida por ela própria; afinal, não podemos esquecer que Ponciá é "elo e herança de uma memória reencontrada pelos seus"30. Parece-me que esse vazio pode ser associado ao que chamamos de banzo. Sobre isso, Gilberto Freyre dirá em Casa Grande e Senzala:

\begin{abstract}
Mas não foi toda de alegria a vida dos negros, escravos dos ioiôs e das iaiás brancas. Houve os que se suicidaram comendo terra, enforcando-se com ervas e potagens dos mandingueiros. $O$ banzo deu cabo de muitos. $O$ banzo - a saudade da África. Houve os que de tão banzeiros ficaram lesos, idiotas. Não morreram: mas ficaram penando. E sem achar gosto na vida normal entregando-se a excessos, abusando da aguardente, da maconha, masturbando-se. ${ }^{31}$
\end{abstract}

O texto de Freyre reduz o significado do banzo à saudade de África e sugere que houve mais alegrias que sofrimentos na escravidão, como se os sofrimentos fossem apenas um detalhe na vida dos negros escravizados. Bem, sabemos que isso está longe de ser verdade, e o próprio Freyre dirá o banzo deu cabo de muitos. Mas o banzo é apenas uma grande tristeza? Uma nostalgia que mata? Um tipo de melancolia? Davi Nunes afirma que não trata apenas disso:

O banzo é mais que isso, conflui em si todas essas palavras em português que remete a um estado de desassossego na alma, convulsionadas por uma exterioridade de terror, morte, escravidão, tortura. É a síntese profunda de uma existência moída em dor por uma estrutura social, política e econômica aterrorizadora. ${ }^{32}$

Davi Nunes acrescenta que o banzo:

\footnotetext{
${ }^{29}$ Ibidem, p. 45.

${ }^{30}$ Ibidem, p. 128.

${ }^{31}$ Gilberto Freyre, Casa grande \& senzala (1933), 2003, p. 552-553.

32 Davi Nunes, Banzo: Um estado de espírito negro, 2018, n.p.
} 
Não era/é necessariamente o fim da vida, mas a manutenção de um estado de alma que não lhe fazia funcionar para uma estrutura de opressão. Um exemplo nítido disso é a loucura, enlouquecer na escravização minava a ordem, o louco era fogo ensandecido mesmo que fosse para a morte. ${ }^{33}$

Trata-se disso o vazio de Ponciá, uma espécie de banzo. Esse banzo levará a personagem, ao fim da narrativa, ao excesso da loucura - quando se cumprirá a herança que Vô Vicêncio lhe deixara.

\section{O entre-lugar de Ponciá-Vicêncio}

Voltemos agora à epígrafe deste ensaio: "Falar, escrever, significa falar contra, escrever contra"34 - Santiago afirma ao pensar o entre-lugar do discurso latino americano. Para ele, uma literatura latino-americana está ligada "à uma geografia de assimilação e de agressividade, de aprendizagem e de reação, de falsa obediência"35. Para Santiago, a literatura latino-americana, está em um entrelugar, já que não podemos nos desvencilhar da invasão estrangeira (ocidentaleuropeia), mas também não podemos retornar a uma origem pura, uma condição de paraíso. Nesse sentido, a literatura latino-americana, estaria:

Entre o sacrifício e o jogo, entre a prisão e a transgressão, entre a submissão ao código e a agressão, entre a obediência e a rebelião. Entre a assimilação e a expressão - ali, nesse lugar aparentemente vazio, seu templo e seu lugar de clandestinidade, ali, se realiza o ritual antropófago da literatura latinoamericana. ${ }^{36}$

Tomo aqui o conceito de Silviano Santiago para pensar também a potência desse entre-lugar da literatura afro-brasileira, e mais especificamente o romance Ponciá Vicêncio de Conceição Evaristo, que não pode ser uma literatura brasileira original e pura já que prescinde à existência/leitura dos tais clássicos já caracterizados neste ensaio - os textos que sempre estiveram disponíveis com maior facilidade (e já que nem mesmo esses clássicos ou cânones brasileiros

\footnotetext{
${ }^{33}$ Ibidem, n.p.

${ }^{34}$ Silviano Santiago, "O entre-lugar do discurso latino-americano", 2000, p. 17.

${ }^{35}$ Ibidem, p. 16.

${ }^{36}$ Ibidem, p. 26.
} 
seriam puros, como dito por Silviano Santiago). Um romance que, principalmente, atua no desvio e na transgressão desse cânone e que, só então, aparece como um texto, como um projeto visível, aquele que "é a mensagem, é a ausência no

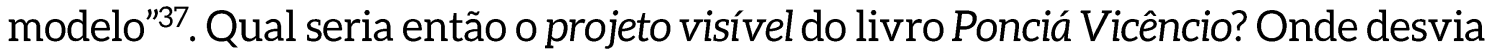
do cânone? Onde rasura as estruturas da literatura brasileira?

Inicialmente, é importante destacar que - diante do cenário apresentado na pesquisa citada por Regina Dalcastagnè, conforme citado no primeiro item desse ensaio - Conceição Evaristo é, ela própria, uma rasura nas estruturas da literatura. Não digo nas estruturas do cânone, já que a mesma não está incluída nesse seleto número de grandes obras, e não foi escolhida para figurar entre os "imortais"38; mas na estrutura da literatura brasileira, esse saber que é quase que "monopolizado pelos homens brancos, sem deficiência, adultos, heterossexuais, urbanos, de classe média"39.

Além disso, e mais importante, a brecha se abre na linguagem utilizada por Conceição Evaristo, que privilegia uma escrita mais próxima da fala; ou na estrutura do próprio romance, que rejeita a linearidade, que prefere a estrutura inconstante da memória na construção da narrativa; ou ainda nos desvios às representações comuns à literatura canônica, ao escrever um romance em que todos os personagens são negros, participantes da diáspora africana a partir da rememoração de seus antepassados. Aqui, em Ponciá Vicêncio, o corpo/sujeito negro fala, os sofrimentos do povo negro durante a escravidão não são uma ressalva (como em Freyre). Já no pós-abolição esses sofrimentos são reencenados por Ponciá Vicêncio e seus familiares e, a partir disso, o livro vai denunciar o racismo sofrido pelo povo negro. Não um racismo direcionado de um indivíduo

\footnotetext{
${ }^{37}$ Ibidem, p. 25.

${ }^{38} \mathrm{Em} 2018$, apesar de uma forte campanha na internet que contou com 22,6 mil assinaturas a favor de Conceição Evaristo tornar-se uma "imortal", a escritora premiada, que disputou a vaga da $7^{\circ}$ cadeira da Academia Brasileira de Letras, teve apenas 1 voto, enquanto o cineasta Cacá Diegues, vencedor, teve 22 votos (entre os 35 totais). A Academia Brasileira de Letras possui, entre seus membros, 1 homem negro, 5 mulheres brancas e 33 homens brancos.

${ }^{39}$ Regina Dalcastagnè, Literatura brasileira contemporânea: um território contestado, 2016, n.p.
} 
para outro, mas um racismo de Estado, que, segundo Foucault, faz "o corte entre o que deve viver e o que deve morrer" 40 .

Para Foucault, o racismo existe há muito tempo, mas foi a emergência do biopoder, introduzido no fim do século XVIII e início do século XIX, que permitiu que o racismo se tornasse um mecanismo de Estado:

O que inseriu o racismo nos mecanismos do Estado foi mesmo a emergência desse biopoder. Foi nesse momento que o racismo se inseriu como mecanismo fundamental do poder, tal como se exerce nos Estados modernos, e que faz com que quase não haja funcionamento moderno do Estado que, em certo momento, em certo limite e em certas condições, não passe pelo racismo. ${ }^{41}$

A biopolítica é uma tecnologia de poder em que, a partir de um saber-poder médico/biológico, o Estado regulamenta a vida de uma população. Trata-se de fazer viver e deixar morrer. O racismo será inserido como mecanismo de Estado com a função de fragmentar e efetuar um corte: de um lado, estará quem pode morrer (as raças inferiores) e, de outro, quem deve viver (as raças superiores). Foucault afirma que se trata de uma relação biológica no sentido que "a morte do outro não é simplesmente a minha vida, na medida em que seria minha segurança pessoal; a morte do outro, a morte da raça inferior (ou do degenerado, ou do anormal), é o que vai deixar a vida em geral mais sadia" ${ }^{2}$. Nesse sentido, o Estado poderá assumir uma função assassina quando tiver o objetivo de eliminar um perigo biológico. Assim, o racismo será a condição de aceitabilidade para a retirada da vida pelo Estado. ${ }^{43}$ Destaco que Foucault não pensa apenas na possibilidade de um assassinato direto do Estado - nas balas policiais que matam a juventude negra -, "mas também tudo o que pode ser assassínio indireto: o fato de expor à morte, de multiplicar para alguns o risco de morte ou, pura e simplesmente, a morte política, a expulsão, a rejeição, etc." ${ }^{44}$.

\footnotetext{
${ }^{40}$ Michel Foucault, "Aula de 17/03/1976", 2002, p. 304.

${ }^{41}$ Ibidem, p. 304.

${ }^{42}$ Ibidem, p. 305.

${ }^{43}$ Ibidem, p. 306.

${ }^{44}$ Ibidem, p. 306.
} 
Conceição Evaristo denuncia o racismo de Estado, que mata indiretamente o povo negro, ao escrever Ponciá Vicêncio. A morte em Ponciá Vicêncio pode ser ligada à morte dos sonhos, das esperanças de uma vida melhor. Afinal, Ponciá Vicêncio tomara a decisão repentina de sair do povoado onde nascera, pois estava cansada da exploração:

De trabalhar o barro com a mãe, e de ir e vir às terras dos brancos e voltar de mãos vazias. De ver a terra dos negros coberta de plantações, cuidadas pelas mulheres e crianças, pois os homens gastava, a vida trabalhando nas terras dos senhores, e depois a maior parte das colheitas ser entregue aos coronéis. Cansada da luta insana, sem glória, a que todos se entregavam para amanhecer cada dia mais pobres, enquanto alguns conseguiam enriquecer-se a todos dia. Ela acreditava que poderia traçar outros caminhos, inventar uma vida nova. E avançando sobre o futuro, Ponciá partiu no trem do outro dia, pois tão cedo a máquina não voltaria ao povoado. Nem tempo de se despedir do irmão teve. E agora, ali deitada de olhos arregalados, penetrados no nada, perguntava-se se valera ter deixado a sua terra. O que acontecera com os sonhos tão certos de uma vida melhor? Não eram somente sonhos, eram certeza! Certezas que haviam sido esvaziadas no momento em que perdera o contato com os seus. Eagora feito morta-viva, vivia. ${ }^{45}$

Os sonhos de Ponciá vão se esvaziando diante das dificuldades de conter os sofrimentos, de fazer uma vida melhor para ela e para os seus, quando percebe, ao voltar ao povoado, que nada ou muito pouco mudara desde a Lei Áurea e que a escravidão continuava: "Todos, ainda, sob o julgo de um poder que, como Deus, se fazia eterno" 46 :

Ela mesma havia chegado à cidade com o coração a sobrar esperança [...] crente em sucessos e eis no que deu. Um barraco no morro. Um ir e vir para a casa das patroas. Umas sobras de roupas e de alimento para compensar o salário que não bastava. ${ }^{47}$

Esvaziada de sonhos, Ponciá se preenche de vazio.

Esse apartar-se de si mesma, que chamo de banzo, vai se tornando mais frequente, principalmente a partir da migração de Ponciá Vicêncio para a cidade. Ponciá está excluída da lógica universalizante das metrópoles na sociedade do

\footnotetext{
${ }^{45}$ Conceição Evaristo, Ponciá Vicêncio, 2003, p. 33-34.

${ }^{46}$ Ibidem, p. 49.

${ }^{47}$ Ibidem, p. 82.
} 
controle caracterizada por Peter Pál Pelbart ${ }^{48}$, essa sociedade que, por sua fluidez, permite que um sujeito como Ponciá chegue até a cidade, mas que, ao mesmo tempo, a exclui (ela seria uma entre os muitos sujeitos não comportados pelo capitalismo global). Sobre esse sistema, Pelbart dirá que tenta "tornar rentável a totalidade do tempo, evitando que o tempo se escoe em tempo perdido"; nesse sentido, "o tempo livre virou tempo escravizado, tempo investido em ganhar tempo"49.

Como poderia Ponciá Vicêncio fazer parte de um sistema que novamente escraviza? Ao contrário, ela se tornará um sujeito inempregável, o banzo não lhe permite que seja escrava do tempo; nas suas ausências, ela perde a noção de tempo. O banzo, nesse sentido, não é apenas uma consequência dos sofrimentos, da rememoração da personagem - o banzo é também resistência. Assim como seus antepassados escravizados, que não assimilavam a vida escrava e se apartavam dela através do banzo, Ponciá resiste a uma sociedade que quer novamente escravizá-la. O banzo, então, deixa de ser um problema e passa a ser uma vontade da personagem:

Ponciá Vicêncio não queria mais nada com a vida que lhe era apresentada. Ficava olhando sempre um outro lugar de outras vivências. Pouco de dava se fazia sol ou se chovia. Quem era ela? Não sabia dizer. Ficava feliz e ansiosa pelos momentos de auto ausência. ${ }^{50}$

Avanço ainda mais na ideia do banzo como resistência. Em Ponciá Vicêncio, o vazio é mais do que simples ausência, resistência ao mundo universalizante que tenta escravizar sem tempo. O vazio de Ponciá, de alguma forma, a leva de volta aos seus antepassados, através de choros e risos (como seu avô).

Assim, entendo que a derradeira libertação de Ponciá Vicêncio da vida escrava foi quando do seu encontro novamente com o rio. Nesse momento,

\footnotetext{
48 Peter Pál Pelbart, "Da claustrofobia contemporânea: Sobre o fim da exterioridade no capitalismo tardio", 2000.

${ }^{49}$ Ibidem, p. 34.

${ }^{50}$ Conceição Evaristo, Ponciá Vicêncio, 2003, p. 90.
} 
Ponciá, já completamente preenchida pelo vazio libertador que lhe permite trazer para o seu corpo as memórias dos seus antepassados, encontra a energia para viver. Essa energia vem das memórias de seus antepassados, presentes em seu vazio constituinte e agora preservados para sempre nas águas do rio. Ponciá cumpre a herança que seu avô lhe deixou - a loucura:

Chorava, ria, resmungava. Desfiava fios retorcidos de uma longa história. Andava em círculos, ora com uma das mãos fechadas e com o braço para trás, como se fosse cotoco, ora com as duas palmas abertas, executando calmos e ritmados movimentos, como se estivesse moldando alguma matéria viva. ${ }^{51}$

Chorava e ria porque o passado dos seus era de desespero e sofrimento, mas era também repleto de ternura, amor. Ponciá

[...] andava como se quisesse emendar um tempo ao outro, seguia agarrando tudo, o passado-presente-e-o-que-há-de vir. [...] Ponciá Vicêncio, elo e herança de uma memória reencontrada pelos seus, não se perderia jamais, se guardaria nas águas do rio. ${ }^{52}$

Através de Ponciá, as memórias dos antepassados africanos e escravos, antepassados negros, aqueles que resistiram de todas as formas contra o poder branco/colonizador, estariam bem guardadas, preservadas pelas águas do rio. Essa preservação não é retorno a um ideal que está localizado no passado, mas rememoração de um passado esquecido para possibilitar um devir, um vir a ser do povo negro. Ponciá Vicêncio, corpo aquático prenhe de memórias, devém mulher, devém rio; que devirá mar.

\section{Conclusão}

Conceição Evaristo narra a história de Ponciá com uma beleza dura; uma poesia que não acalma - que movimenta, mobiliza. Ela, de seu lugar de mulher negra, conta a história dessa personagem, expressando e não representando a mulher negra - como faz na Literatura Canônica. O romance Ponciá Vicêncio de

\footnotetext{
${ }^{51}$ Conceição Evaristo, Ponciá Vicêncio, 2003, p. 127.

${ }^{52}$ Ibidem, p. 128.
} 
Conceição Evaristo é um livro que grita as mazelas, os sofrimentos, as angústias, os vazios do povo negro; realidade que se perpetua através dos anos e que permanece gritante nos tempos atuais. Eu diria que o romance vai muito além de mostrar sofrimentos: expressa as formas resistência de um "povo-menor, eternamente menor, tomado num devir-revolucionário"53 contra a realidade de dominação branca. Resistências que sempre ocorreram, afinal, desde a escravidão, a exploração nunca foi aceita passivamente. Várias sempre foram as formas de luta: rebeliões, suicídios, abortos, quilombos, o banzo, etc.

Entendo que o romance Ponciá Vicêncio está no entre-lugar da literatura brasileira, esse entre próprio do devir. A literatura feita por Conceição Evaristo desvia do projeto de cânone. Seu projeto visível, aquilo de revolucionário que há na obra, opera no sentido de rasurar as representações do povo negro próprias do cânone, que fizerem desse Outro a sombra do Eu. Pretende impedir novos silenciamentos, reavivando memórias, seja dos sofrimentos, seja das lutas. Nesse sentido, o fim de Ponciá Vicêncio nos sugere que a verdadeira libertação dos negros só se cumprirá quando as memórias dos antepassados, por mais dolorosas que possam ser, forem lembradas, quando elas não mais puderem ser esquecidas. Sobre a importância da herança, Derrida diria:

[...] é preciso fazer de tudo para se apropriar de um passado que sabemos no fundo permanecer inapropriável, quer se trate aliás de uma memória filosófica, da precedência de uma língua, de uma cultura ou da filiação em geral. Reafirmar, o que significa isso? Não apenas aceitar essa herança, mas relançá-la de outra maneira e mantê-la viva. Não escolhê-la (pois o que caracteriza a herança é primeiramente que não é escolhida, sendo ela o que nos elege violentamente), mas escolher preservá-la viva. ${ }^{54}$

O romance Ponciá Vicêncio, de Conceição Evaristo, preserva viva a herança do povo negro, gritando forte contra as violências sofridas por este desde a escravidão e, especialmente, pelo corpo negro feminino. O livro-grito Ponciá Vicêncio ecoa nos ouvidos dos leitores despreocupados. De forma poética, faz com que o nosso corpo se movimente com os sofrimentos e ternuras do povo negro

${ }^{53}$ Gilles Deleuze, "A literatura e a vida", 1997, p. 14.

${ }^{54}$ Jacques Derrida, De que amanhã: diálogo Jacques Derrida \& Elizabeth Roudinesco, 2004, p. 14. 
presentes no texto e na história. Conceição Evaristo, ao escrever Ponciá Vicêncio, sonha ao contrário - se coloca no entre-lugar da literatura brasileira.

\section{Referências}

CALVINO, Italo. Por que ler os clássicos. São Paulo: Companhia das letras, 1993.

CÂNDIDO, Antônio. Formação da literatura brasileira - Vol. 1 (1959). 9. ed. Belo Horizonte: Itatiaia Limitada, 2000.

DALCASTAGNÈ, Regina. Literatura brasileira contemporânea: um território contestado. Formato: eBook Kindle. Vinhedo: Editora Horizonte, 2016.

DERRIDA, Jacques. De que amanhã: diálogo Jacques Derrida \& Elizabeth Roudinesco. Rio de Janeiro: Jorge Zahar Editor, 2004.

EVARISTO, Conceição. Ponciá Vicêncio. Belo Horizonte: Mazza Edições, 2003. . Da grafia-desenho de minha mãe um dos lugares de nascimento de minha escrita. In: Seminário Nacional Mulher e Literatura, XI e Seminário Internacional Mulher e Literatura, II, Rio de Janeiro, 2005. Disponível em: <http://nossaescrevivencia.blogspot.com.br/search/label/apresentacao>. Acesso em: 31 ago. 2018.

DELEUZE, Gilles. A literatura e a vida. In: . Crítica e Clínica. São Paulo: Editora 34, 1997.

DELEUZE, Gilles; GUATARRI, Félix. O que é uma Literatura menor. In: Kafka por uma Literatura Menor. São Paulo: Autêntica, 2014.

FOUCAULT, Michel. Aula de 17/03/1976. In: Em defesa da sociedade. São Paulo: Martins Fontes, 2002.

FREYRE, Gilberto. Casa grande \& senzala (1933). 48. ed. São Paulo: Global, 2003. 
HALL, Stuart. Identidade cultural e diáspora. Revista do Patrimônio Histórico Artístico Nacional, Rio de Janeiro, n. 24, p. 68-74, 1998.

NUNES, Davi. Banzo: um estado de espírito negro. Atualizado em 30 abr. 2018. Disponível em: <https://www.geledes.org.br/banzo-um-estado-de-espiritonegro/>. Acesso em: 30 set. 2018.

PELBART, Peter Pál. Da claustrofobia contemporânea: Sobre o fim da exterioridade no capitalismo tardio. In: A vertigem por um fio. São Paulo: Editora Iluminuras, 2000.

ROMERO, Silvio. História da literatura brasileira: fatores da literatura brasileira. 1888. Disponível em:

$<$ http://www.dominiopublico.gov.br/pesquisa/DetalheObraForm.do?select_act ion $=\&$ co_obra $=2128>$. Acesso em: 30 set. 2018.

SAID, Edward. O âmbito do orientalismo. In: . Orientalismo. São Paulo: Companhia das Letras, 1990.

SANTIAGO, Silviano. O entre-lugar do discurso latino-americano. In:

Uma literatura nos trópicos: ensaio sobre a independência. Rio de Janeiro: Rocco, 2000.

SOUZA, Lívia Maria Natália de. Uma reflexão sobre os discursos menores ou a escrevivência como narrativa subalterna. Revista Crioula, São Paulo, v. 21, p. $25-$ 43, 2018. Disponível em: <https://doi.org/10.11606/issn.19817169.crioula.2018.146551>. Acesso em: 31 ago. 2018.

SPIVAK, Gayatri Chakravorty. Pode o subalterno falar? Belo Horizonte: Editora UFMG, 2010.

Referência para citação deste artigo

DUARTE, R. O entre-lugar de Ponciá Vicêncio: $O$ vazio como resistência. Revista PHILIA |Filosofia, Literatura \& Arte, Porto Alegre, volume1, número 1,182 - 201, fevereiro de 2019. 